\title{
Lnc-RNA UCA1 Promotes TGF- $\beta$-Mediated Epithelial-Mesenchymal Transition via Inhibiting miR-204 in Gastric Cancer Cells
}

\section{Ding-Fu Zhong}

Jinhua Manicipal People's Hospital

\section{Dan Chen}

Jinhua Municipal Central Hospital

\section{Ying Nie}

Jinhua Polytechnic

\section{Hong-Ying Zhang}

Jinhua Manicipal People's Hospital

Yi Yang

Jinhua Manicipal People's Hospital

Li-Yu Hu (D HLY19820215@163.com )

Jinhua municipal people's hospital

\section{Research}

Keywords: gastric cancer, LncRNA UCA1, miR-204, TGF- $\beta$, epithelial-mesenchymal transition, ZEB1

Posted Date: February 5th, 2021

DOI: https://doi.org/10.21203/rs.3.rs-174304/v1

License: (c) (i) This work is licensed under a Creative Commons Attribution 4.0 International License.

Read Full License 


\section{Abstract \\ Introduction}

Cancer is a genetic modification disease. Since genetic aberrations of gastric cancer are heterogeneous, we assume non-coding RNAs play major roles on gastric cancer phenotypes. Long non-coding RNA (IncRNA) urothelial cancer associated 1 (UCA1) is related with poor prognosis in different cancer types, however, how it works in gastric cancer is unknown.

\section{Methods}

Two gastric cancer cell lines are chosen, MNK45 and SGC-7901. Transforming growth factor- $\beta$ (TGF- $\beta$ ) is used to promote epithelial-mesenchymal transition (EMT) by using cancer cell invasion assay. The transmembrane cell quantities are counted and ZEB1, slug, vimentine and E-Cadherin gene expression levels are measured by quantitative PCR assay. siRNA of UCA1 and miR-204 are used to confirm crosstalk among TGF- $\beta$, UCA1 and miR-204.

\section{Results}

TGF- $\beta$ significantly increases gastric cancer cell transmembrane ability and expression levels of four EMT related genes. These increases can be counteracted by using siRNA of UCA1, suggesting that UCA1 is upstream factor of TGF- $\beta$ signaling pathways and positively regulates it. miRNA-204 alone can inhibit ZEB1 gene expression, however, this inhibition can be demolished by UCA1, suggesting that UCA1 sponges miR-204 to prevent its function from inhibiting ZEB1.

\section{Conclusions}

miR-204 could be used as an indicator of prognosis of gastric cancer. The higher miR-204 expression levels, the less possibility to develop EMT. Meanwhile, UCA1 inhibitors can be considered as potential genetic medical drugs.

\section{Introduction}

Cancer is basically a genetic modification disease resulting in aberrant cellular homeostasis and successive growth. The discovery of protein-coding genetic mutations established our principles of understanding how these exome aberrances drove pathogenesis of tumor. However, only protein-coding sequence mutations cannot solely explain why and how cancer is generated and developed. Since the coding sequences account for only $2 \%$ of the whole genome, it is reasonable to assume that the noncoding sequences play major roles on the cancer phenotypes. 
All genes in human are transcribed into RNA, which dominantly are noncoding RNAs [1, 2]. Long noncoding RNAs (IncRNA) are transcripts $>200$ nucleotides with no protein translation potentials [3, 4]. It is recognized that IncRNAs are delicately regulated and restricted to certain cell types [5]. The biological functions of majority of the IncRNAs remain un-discovered. MicroRNAs (miRNAs) bind to 3'-untranslated region (3'UTR) of mRNAs of target genes, resulting in the degradation of mRNAs or the suppression of translation process $[6,7]$. The involvement of miRNAs in regulating tumors malignancies had been reported by plenty of researchers.

Gastric cancer is the most common subtype of gastrointestinal cancer worldwide. It is the fifth most common type of cancer and the third in mortality comparing with all other cancer types [8]. According to report in 2015 of National Central Cancer Registry of China (NCCRC), gastric cancer is the second both in incidence rate and mortality in China [9]. The five-years survival rate of gastric cancer is below $30 \%$ [10, 11]. Patients with gastric cancer are often diagnosed at the intermediate or even terminal stages of the disease with liver, lymph nodes or lung metastasis, which hinders efficiency of the treatment and contributes to the low five-years survival rates. The transforming growth factor- $\beta$ (TGF- $\beta$ ) is the key factor in the gastric tumor micro-environment. By stimulating vascular endothelial growth factor C (VEGF-C), TGF- $\beta$ signaling pathway stimulates lymph-angiogenesis, increases invasion ability of the tumor cells and promotes epithelial-mesenchymal transition (EMT) [12-14]. Slug, ZEB1, Vimentine, and E-cadherin are proved to be related with the EMT process [15]. To understand how the TGF- $\beta$ signaling pathway delicately regulates metastasis of gastric cancer would definitely provide strong evidence to support excise therapy in clinic.

LncRNA urothelial cancer associated 1 (UCA1) is highly expressed in variant tumor cells, such as bladder cancer and oral squamous cell carcinoma, and associated with bad prognosis of the diseases [16-18]. But its impact on gastric cancer is unclear. As a possible target of UCA1, recent studies have shown that miR-204 expressed significantly low in several tumors including colorectal cancer [19]. However, the potential role of miR-204 in gastric cancer is largely unknown. The purpose of this study is to investigate whether and how IncRNA UCA1 and miR-204 participate in the TGF- $\beta$ stimulated EMT in two gastric cancer cell lines.

\section{Materials And Methods Cell Culture}

Gastric cancer cell lines, MNK-45 and SGC-7901 were purchased from ATCC. Cells are cultured in DMEM medium with $10 \%$ fetal bovine serum, $100 \mathrm{U} / \mathrm{ml}$ penicillin, $100 \mu \mathrm{g} / \mathrm{ml}$ streptomycin, at $37^{\circ} \mathrm{C}$ incubator with $5 \%$ carbon dioxide. Cell expansion and splitting process is restrictedly performed according to the manufacture's protocol.

\section{Tumor Cell Invasion Assay}


When the culture flask is $70-80 \%$ confluent, the gastric cancer cells are cultured with DMEM medium without fetal bovine serum overnight. Recombinant human TGF- $\beta 1$ is purchased from PeproTech (Cat:100-21c). $10 \mathrm{ng} / \mathrm{ml}$ TGF- $\beta 1$ is added into the cell culture medium and incubated for 48 hours.

After being digested with trypsin, the gastric cells are calculated and put in ice for further usage. $600 \mu \mathrm{l}$ DMEM medium with $15 \%$ fetal bovine serum is added into the bottome of the transwells, subsequently cell suspension is added into the membrane at $2 \times 10^{5}$ concentration. Incubate at $37^{\circ} \mathrm{C}$ incubator overnight. After getting rid of the floating cells at the bottom of the transwells, the cells adherent to the bottom of transwells are fixed with $50 \%$ methanol for 15 minutes, and washed with PBS solution for three times. Then stained with crystal violet solution for 30 minutes. After being air-dryed, the transwells are observed and six zones are chosen randomly under microscope.

\section{Quantitative RT-PCR}

Trizol is used to extract total RNA from the gastric cancer cells according to standard protocol [14]. cDNA is synthesized by using PrimeScript RT kit from Takara Bio Inc (Cat: DRR014A). SYBR green real-time PCR kit (Applied Biosystems) was used to quantify gene expression levels. Data were analyzed with SDS Relative Quantification Software version 2.2.2 (Applied Biosystems). Ct values were exported into Excel software for data analysis.

Primers for slug gene are: 5'- AGC AGT TGC ACT GTG ATG CC-3', 5'-ACA CAG CAG CCA GAT TCC TC-3'. Primers for E-Cadherin are: 5'-GAG AGC GGT GGT CAA AGA GC-3', 5'-GAG GAG TTC AGG GAG CTC AG- 3'. Primers for ZEB1 are: 5'- GCA CCT GAA GAG GAC CAG AG-3', 5'- TGC ATC TGG TGT TCC ATT TT-3'. Primers for Vimentine are: 5'-TGT CCA AAT CGA TGT GGA TGT TTC-3', 5'-TTG TAC CAT TCT TCT GCC TCC TG-3'. Primers for internal control Gapdh are: 5'-GGG AGC CAA AAG GGT CAT-3', 5'-GAG TCC TTC CAC GAT ACC AA- $3^{\prime}$. The quantitative PCR conditions are: $95^{\circ} \mathrm{C}$ for 5 minutes, followed by 35 cycle of $95^{\circ} \mathrm{C} 30$ seconds and $60^{\circ} \mathrm{C} 34$ seconds, and extension temperature $72^{\circ} \mathrm{C}$ for 5 minutes. The calculation for relative gene expression quantities is based on $2^{-\Delta \Delta C t}$ formation.

\section{Plasmid, miRNA-204 mimic and UCA1 siRNA construction}

miRNA-204 mimics and control mimics, UCA1 siRNA and its control mimics are synthesized by Shanghai Gene Pharma Co, Ltd). Two siRNA sequences of UCA1 are synthesized, siUCA1-1: GCC ATA TGA AGA CAC CCT A;siUCA1-2: TTA ATC CAG GAG ACA AAG A. UCA1 cDNA sequence is cloned into pcDNA3.1. Lipofectamine 3000 was purchased from Invitrogen, and transfection is performed according to the manufacture's protocol.

\section{Statistics Analysis}

Average and standard deviation data were analyzed in Excel. T test is used for significance study. $\mathrm{P}<$ 0.05 considered as significance. Univariate analysis of variance is used by using SPSS 10.0.

\section{Results}




\section{TGF- $\beta$ enhances gastric tumor cell invasion}

After being incubated with $10 \mathrm{ng} / \mathrm{ml}$ TGF- $\beta$, Transwell-Matrigeal trans-membrane assay is performed, and subsequently cells stayed at the bottom of the transwells are stained with crystal violet. Multiple negative controls are used. Six random visions under microscope are took into account, and the numbers of stained cells are calculated and compared.

As shown in Fig. 1, for the MNK-45 and SGC-7901 cell lines, there are both significant more cells went through membrane once treated with TGF- $\beta$ than non-treated cells $(p<0.05)$.

\section{TGF- $\beta$ treatment promotes EMT}

We use the MNK-45 cell line to study how the EMT related genes change their expression levels due to its significant enhanced transmission ability by TGF- $\beta$ treatment. After being treated with TGF- $\beta$ for 24 hours, in the MNK-45 cells, the slug, ZEB1, vimentine, and E-Cadeherin gene expression levels are $3.93 \pm 0.35$, $5.10 \pm 0.17,3.67 \pm 0.21,0.50 \pm 0.10$ times comparing with the negative control cells $(P<0.05)$ (Fig. 2$)$. By using quantitative PCR assay, we demonstrate that TGF- $\beta$ treatment can increase slug, ZEB1 and vimentine gene levels and decrease E-Cadherin expression levels significantly $(P<0.05)$.

\section{Blockage of UCA1 inhibits TGF- $\beta$ induced activation of EMT}

To analyze whether IncRNA UCA1 interferes with the TGF- $\beta$ signaling pathway, several siRNAs of UCA1 (si-UCA1) and negative control siRNAs of UCA1 (NC-si-UCA1) are tested upon MNK-45 cells. The si-UCA1 chosen to use in the subsequent experiments can block $70 \%$ of UCA1 expression $(0.30 \pm 0.05)$. The NC-siUCA1 does not interfere with UCA1 expression at all (data not shown).

Then the si-UCA1 and NC-si-UCA1 are infected into the MNK-45 cells in separate culture plates. After that, we repeat the transwell-matrigeal invasion assay. The study is paralleled with three groups: negative control (NC-si-UCA1), TGF- $\beta$, TGF- $\beta+$ si-UCA1. The results of the TGF- $\beta$ group are shown in Fig. 2 . In the TGF- $\beta+$ si-UCLA1 group, slug, ZEB1, Vimentine and E-Cadherin gene expression levels are $2.05 \pm 0.52$, $2.41 \pm 0.61,0.71 \pm 0.23,2.52 \pm 0.65$ (Fig. 3 ). Comparing with the increase caused by TGF- $\beta$, the blockage of UCA1 significantly depresses the TGF- $\beta$ related gene expression $(P<0.01)$.

\section{UCA1 works through miR-204 to regulate ZEB1 expression}

To test whether UCA1 works with miR-204, the MNK-45 cells are transfected with three groups of genes: miR-204, miR-204 + 5ng UCA1 plasmid, and miR-204 + 10ng UCA1 plasmid. Subsequently, qPCR is used to measure the gene expression levels of ZEB1. We set up the ZEB1 gene expression level in MNK-45 cells is 1. miR-204 transfection reduces ZEB1 expression to $0.24 \pm 0.03$. 5ng UCA1 and 10ng UCA1 can rescue ZEB1 expression to $1.05 \pm 0.10$ and $1.21 \pm 0.23$. These results suggest that miR-204 negatively control ZEB1 expression. 5ng of UCA1 can totally counteract towards miR-204 reduction of ZEB1, suggesting that UCA1 sponged miR-204 to reduce its function (Fig. 4). 


\section{miR-204 directly reduces TGF- $\beta$ induced EMT related gene expression}

Three different combinations of genes are transfected into the MNK-45 cells. There are: TGF- $\beta$, TGF- $\beta+$ miR204, TGF- $\beta$ + miR204 + UCA1. Slug, ZEB1, vimentine, and E-Cadherin expression levels are measured. The result details are shown in Fig. 5 . We demonstrated that miR-204 can directly interact with TGF- $\beta$ and reduces EMT related gene expression levels. This reduction by miR-204 can be counteracted by UCA1.

\section{Discussion}

In this study, we demonstrated that TGF- $\beta$ can significantly increase gastric cancer cell transmission ability and remarkably enhance EMT related gene expression levels. This result is correlated with previous published studies. Down-regulation of E-Cadherin, and increase of vimentin, slug and ZEB1 are the most significant signs of tumor cell transmission. The usage of si-UCA1 can repress vimentin, slug and ZEB1 gene expression and increase E-Cadherin expression. This phenomenon suggests that UCA1 can stimulate TGF- $\beta$ induced EMT in the MNK45 and SGC-7901 gastric cancer cell lines. Further studies are needed to explore whether this phenomenon also happens on gastric tumor tissues.

Recent studies demonstrated aberrant IncRNA UCA1 expression existed in variant carcinomas including bladder cancer, gastrointestinal tumor, neural blastoma and breast cancer [20]. UCA1 attracts miRNA in a competitive way, so called "sponge", in order to free target genes of the miRNA to perform their functions. Interestingly, UCA1 plays through variant pathways. In renal cancer, UCA1 plays a critical regulatory role in proliferation and progression of renal cancer cells by interacting with miR-182-5p/DLL4 axis [21]. In gastric cancer, UCA1 works with miR-7, 495, 498 to promote tumor-genesis [22, 23]. In MNK45 gastric cancer cell line, we demonstrated that UCA1 sponges miR-204 to free its target gene ZEB1 (Fig. 6). It is still early to assume that UCA1 works in a tissue specific way to promote metastasis and thoroughly studies are required to find out its fundamental mechanisms.

Interconversion between epithelial and mesenchymal is highly conserved process during embryogenesis. Epithelial-mesenchymal transition (EMT) is regulated by environmental signals, such as Wnt, TGF- $\beta$, FGF family members and intracellular signaling pathways [24]. EMT related transcription factors (EMT-TF) include zinc finger proteins (e.g., SNAI1, SNAI2), helix-loop-helix transcription factors (e.g., E47), zinc finger and homeodomain protein ZEB1 (also called TCF8 or DeltaEF1) and ZEB2 (also called SIP1). ZEB1/2 may trigger the repression of epithelial genes, such as E-Cadherin, to damage adhesion and tight junctions and the stimulation of mesenchymal factors, such as vimentine, to facilitate trans-

differentiation process. In this study, ZEB1 gene expression level is significantly enhanced and E-Cadherin expression level is nearly at the half level after TGF- $\beta$ treatment in gastric cancer cells. This suggests that TGF- $\beta$ definitely promotes EMT process. Besides ZEB1, vimentine, slug and E-Cadherin, other EMT related genes will be tested in the subsequent studies. 
In this study, we demonstrated the cross-talk among TGF- $\beta$, Inc-UCA1 and miR-204 in gastric cancer cells as shown in Fig. 6. miR-204 inhibits TGF- $\beta$ function, and UCA1 sponges miR-204 to stop its functions. We reasonably suspect that miR-204 expression level could be measured and used to predict prognosis of the gastric cancer. Meanwhile, UCA1 inhibitors might be considered as potential genetic medical drugs, although further and wider explorations are required in the future.

\section{Declarations}

\section{Ethics approval and consent to participate}

Not appliable

\section{Consent for publication}

All authors agree to publish this manuscript in this journal

\section{Availability of data and materials}

Yes

\section{Competing interests}

There are no competing interests for all the authors.

\section{Funding}

This study is funded by Bureau of Science and Technology, Jinhua Municipal (2019A453103).

\section{Authors' contributions}

Dr. Ding-Fu Zhong did most of the lab works. Dr. Dan Chen and Dr. Ying Nie analyzed the data and did the microscope job. Dr. Hong-Ying Zhang and Dr. Yi Yang discussed with Dr. Ding-Fu Zhong and provided very useful suggestions. Dr. Li-Yu Hu wrote the manuscript and the mastermind behind all the lab works.

\section{Acknowledgements}

Not appliable

\section{References}

[1] Morris KV, Mattick JS. The rise of regulatory RNA. Nature reviews Genetics. 2014; 15:423-437.

[2] Rinn JL, Chang HY. Genome regulation by long noncoding RNAs. Annual review of biochemistry. 2012; 81:145-166. 
[3] Iyer MK, Niknafs YS, Malik R, Singhal U, Sahu A, Hosono Y, Barrette TR, Prensner JR, Evans JR, Zhao S, et al. The landscape of long noncoding RNAs in the human transcriptome. Nature genetics. 2015; 47:199-208. [PubMed: 25599403]

[4] Banfai B, Jia H, Khatun J, Wood E, Risk B, Gundling WE Jr, Kundaje A, Gunawardena HP, Yu Y, Xie L, et al. Long noncoding RNAs are rarely translated in two human cell lines. Genome research. 2012; 22:16461657. [PubMed: 22955977]

[5] Cabili MN, Trapnell C, Goff L, Koziol M, Tazon-Vega B, Regev A, Rinn JL. Integrative annotation of human large intergenic noncoding RNAs reveals global properties and specific subclasses. Genes \& development. 2011; 25:1915-1927. [PubMed: 21890647]

[6] Lou, W. et al. MicroRNAs in cancer metastasis and angiogenesis. Oncotarget 8, 115787-115802 (2017).

[7] Banelli, B. et al. MicroRNA in glioblastoma: an overview. Int. J. Genom. 2017, 7639084 (2017).

[8] L.A. Torre, F. Bray, R.L. Siegel, J. Ferlay, J. Lortet-Tieulent, A. Jemal, Global cancer statistics, 2012, CA Cancer J Clin 65(2) (2015) 87-108.

[9] W. Chen, R. Zheng, P.D. Baade, S. Zhang, H. Zeng, F. Bray, A. Jemal, X.Q. Yu, J. He, Cancer statistics in China, 2015, CA Cancer J Clin 66(2) (2016) 115-32.

[10] P. Fugazzola, L. Ansaloni, M. Sartelli, F. Catena, E. Cicuttin, G. Leandro, G.L. De' Angelis, F. Gaiani, F. Di Mario, M. Tomasoni, F. Coccolini, Advanced gastric cancer: the value of surgery, Acta Biomed 89(8-S) (2018) 110-116.

[11] K. Rawicz-Pruszynski, J.W. van Sandick, J. Mielko, B. Cisel, W.P. Polkowski, Current challenges in gastric cancer surgery: European perspective, Surg Oncol 27(4) (2018) 650-656.

[12] Luo J, Chen X, Li P. The Role of TGF-beta and Its Receptors in Gastrointestinal Cancers. Transl Oncol 12(3) (2019) 475-484.

[13] Ikushima H, Miyazono K. TGFbeta signalling: a complex web in cancer progression. Nat Rev Cancer. 2010;10(6):415-24.

[14] Pak KH, Park KC, Cheong JH.VEGF-C induced by TGF- beta1 signaling in gastric cancer enhances tumor-induced lymphangiogenesis. BMC Cancer. 2019 Aug 13;19(1):799.

[15] Dongre A, Weinberg RA. New insights into the mechanisms of epithelial-mesenchymal transition and implications for cancer. Nat Rev Mol Cell Biol. 2019 Feb;20(2):69-84. doi: 10.1038/s41580-018-00804.PMID: 30459476. 
[16] Wang H, Guan Z, He K, Qian J, Cao J, Teng L. LncRNA UCA1 in anti-cancer drug resistance. Oncotarget 8, 64638-64650 (2017).

[17] Pan J, Li X, Wu W, Xue M, Hou H, Zhai W, Chen W. Long non-coding RNA UCA1 promotes cisplatin/gemcitabine resistance through CREB modulating miR-196a-5p in bladder cancer cells. Cancer Lett. 382, 64-76 (2016).

[18] Yang, Y. T. et al. Long non-coding RNA UCA1 contributes to the progression of oral squamous cell carcinoma by regulating the WNT/beta-catenin signaling pathway. Cancer Sci. 107, 1581-1589 (2016)

[19] Padi SK, Zhang Q, Rustum YM, Morrison C \& Guo B. MicroRNA-627 mediates the epigenetic mechanisms of vitamin $D$ to suppress proliferation of human colorectal cancer cells and growth of xenograft tumors in mice. Gastroenterology 145, 437-446 (2013)

[20] W Xuan, H Yu, X Zhang, D Song. Crosstalk between the IncRNA UCA1 and microRNAs in cancer, FEBS Lett 593(15) (2019) 1901-1914.

[21] W. Wang, W. Hu, Y. Wang, Y. An, L. Song, P. Shang, Z. Yue, Long non-coding RNA UCA1 promotes malignant phenotypes of renal cancer cells by modulating the miR-182-5p/DLL4 axis as a ceRNA, Mol Cancer 19(1) (2020) 18.

[22] P. Wang, X. Liu, G. Han, S. Dai, Q. Ni, S. Xiao, J. Huang, Downregulated IncRNA UCA1 acts as ceRNA to adsorb microRNA-498 to repress proliferation, invasion and epithelial mesenchymal transition of esophageal cancer cells by decreasing ZEB2 expression, Cell Cycle 18(18) (2019) 2359-2376.

[23] L. Sun, L. Liu, J. Yang, H. Li, C. Zhang, SATB1 3'-UTR and IncRNA-UCA1 competitively bind to miR495-3p and together regulate the proliferation and invasion of gastric cancer, J Cell Biochem 120(4) (2019) 6671-6682.

[24] Caramel J, Ligier M, Puisieux A. Pleiotropic Roles for ZEB1 in Cancer. Cancer Res. 2018 Jan 1;78(1):30-35.

\section{Figures}




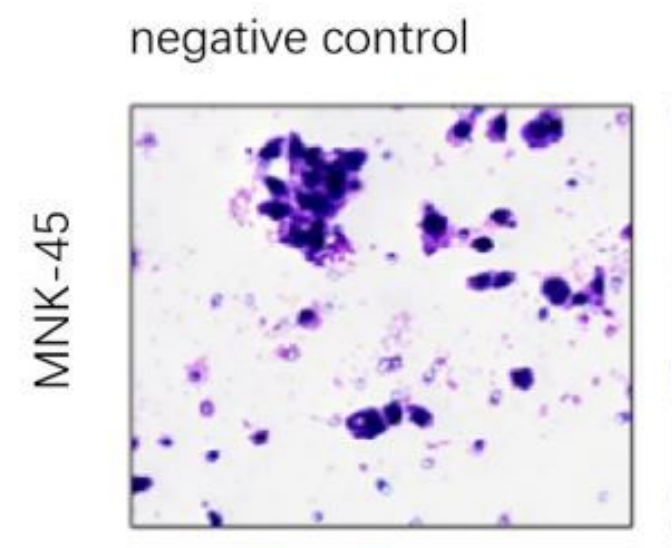

\section{TGF-beta treated}
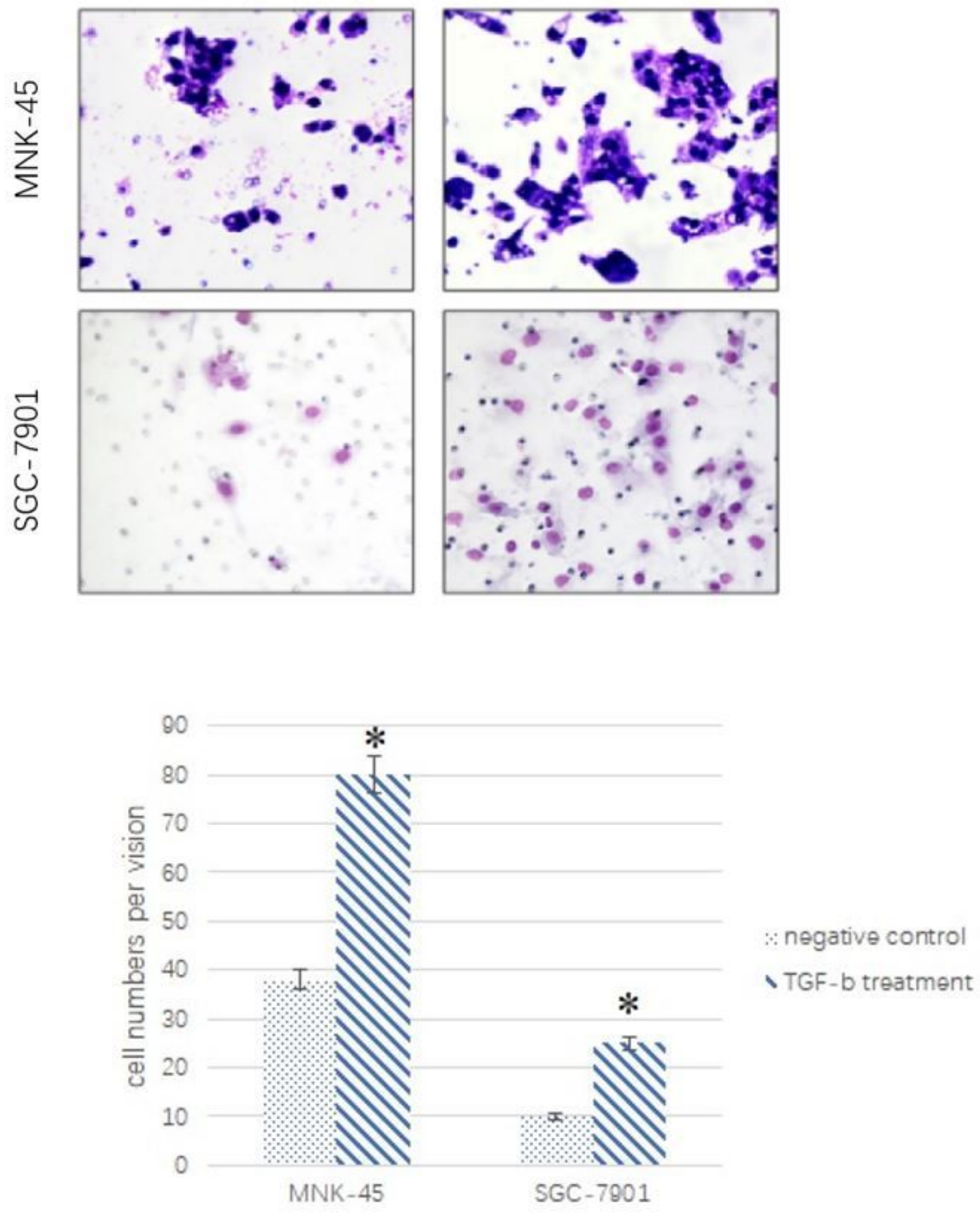

\section{Figure 1}

TGF- $\beta$ enhances gastric cancer cell's invasion ability The cancer cells transmembrane assay is performed. The gastric cells, which can transfer through membrane and stayed at the bottom of flasks are stained with crystal violet solution. Cell numbers are counted in six random visions under microscope. The cell numbers are significantly increased after being incubated with TGF- $\beta(P<0.05)$. 


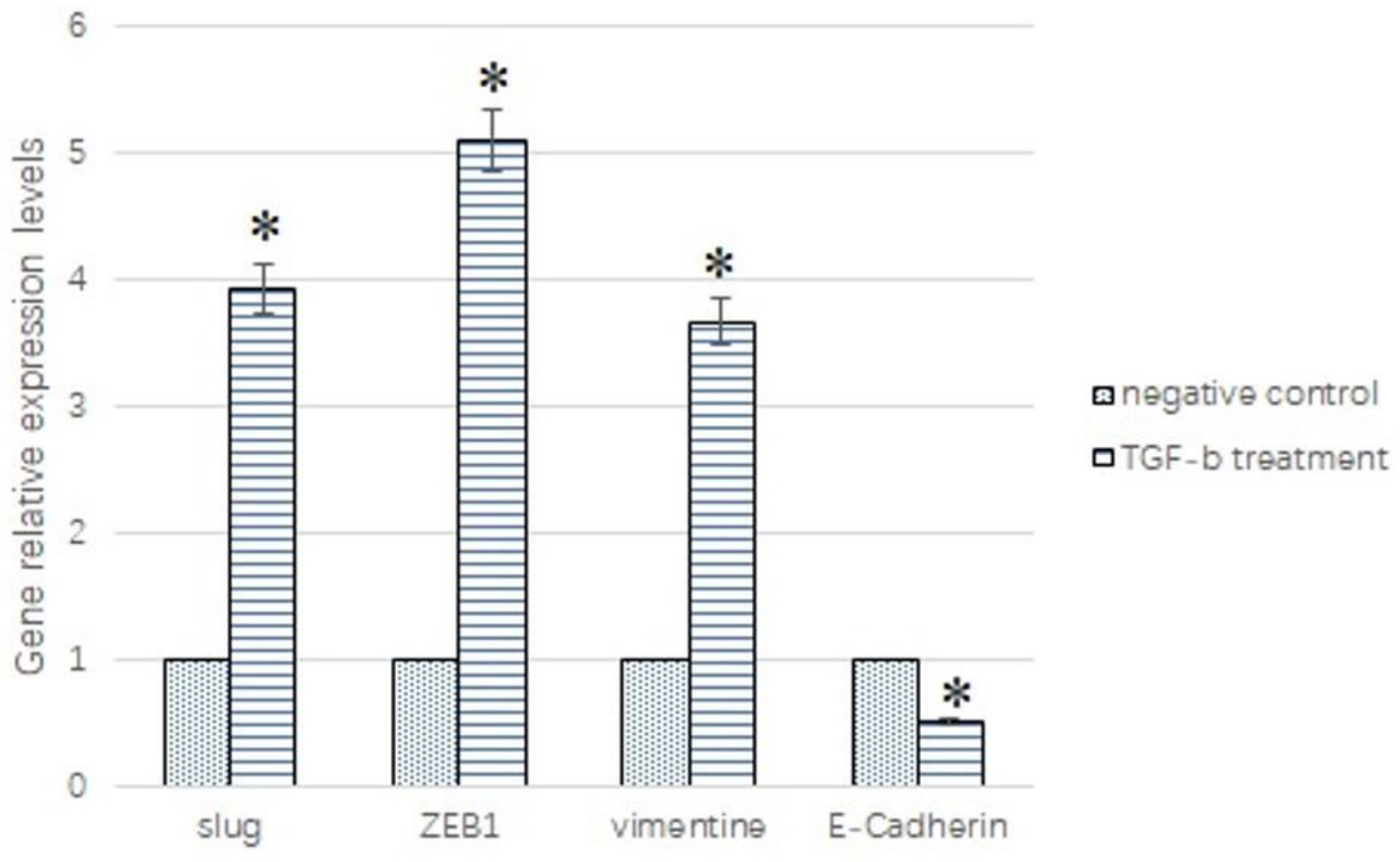

Figure 2

Four EMT related gene expression levels are increased by TGF- $\beta$ Slug, ZEB1, vimentine and E-Cadherin are EMT related genes. Slug, ZEB1 and vimentine expression levels are increased to $3.93 \pm 0.35,5.10 \pm 0.17$, $3.67 \pm 0.21$ respectively. E-Cadherin level is decreased to $0.50 \pm 0.10$. * $P<0.05$. 


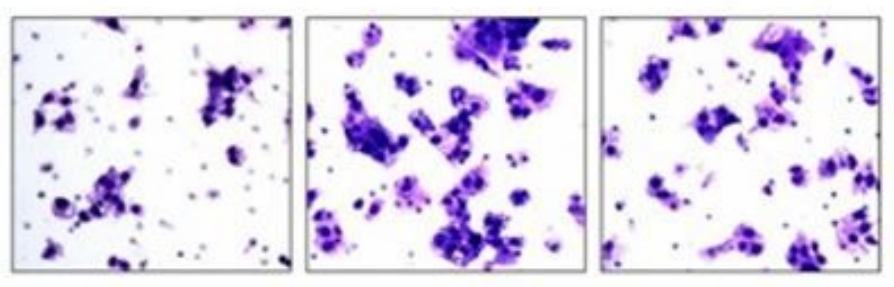

\section{control TGF-beta TGF-beta+siUCA1}
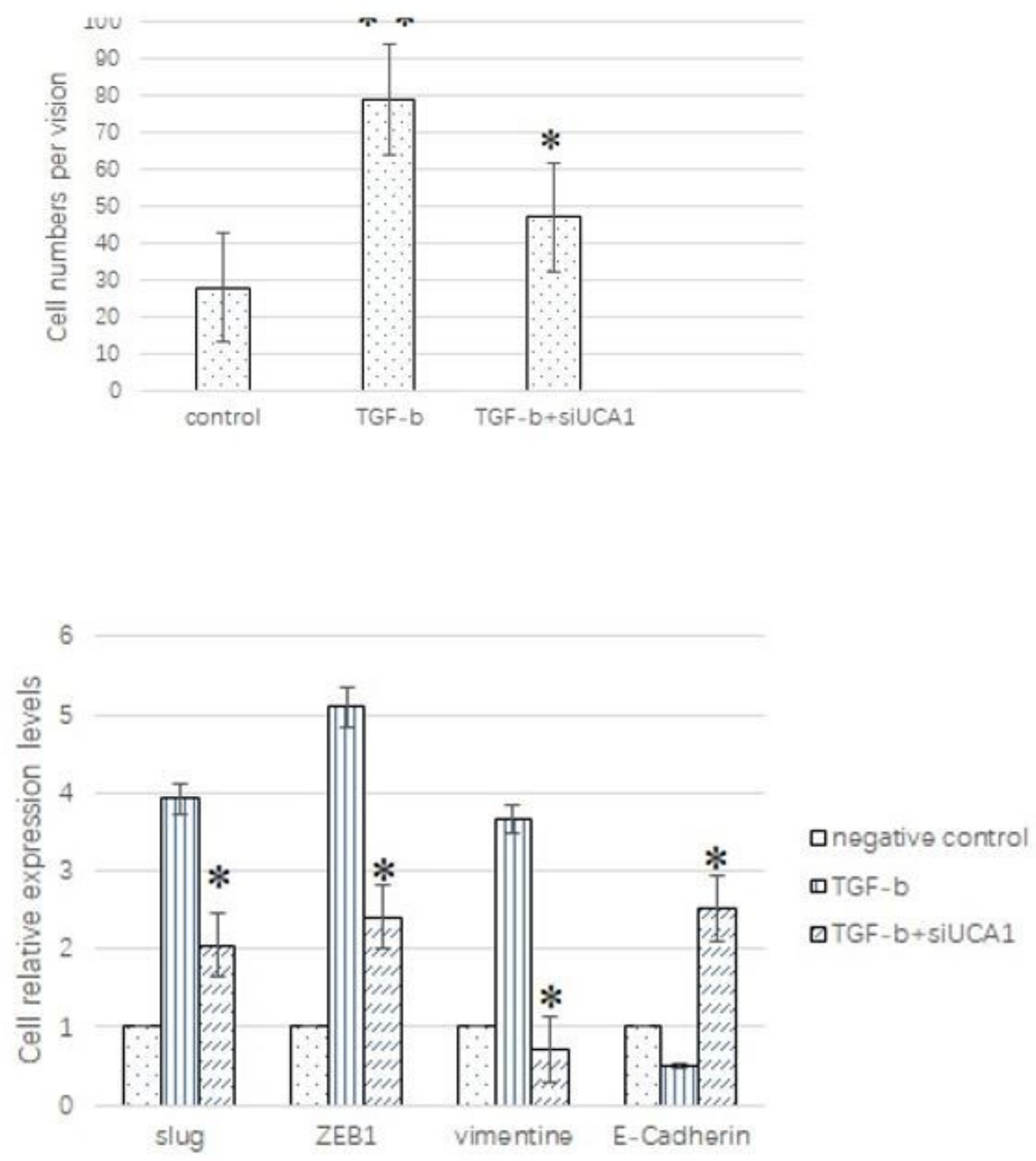

Figure 3

Blockage of UCA1 inhibits TGF- $\beta$ induced activation of EMT siRNA of UCA1 (siUCA1) is added into the cancer cell invasion essay and qPCR. The gastric cell numbers are significantly decreased in the TGF- $\beta$ plus siUCA1 group. The slug, ZEB1 and vimentine expression levels are decreased into $2.05 \pm 0.52$, $2.41 \pm 0.61,2.52 \pm 0.65$. E-Cadherin levels is $0.71 \pm 0.23 .{ }^{*} \mathrm{P}<0.05$. 


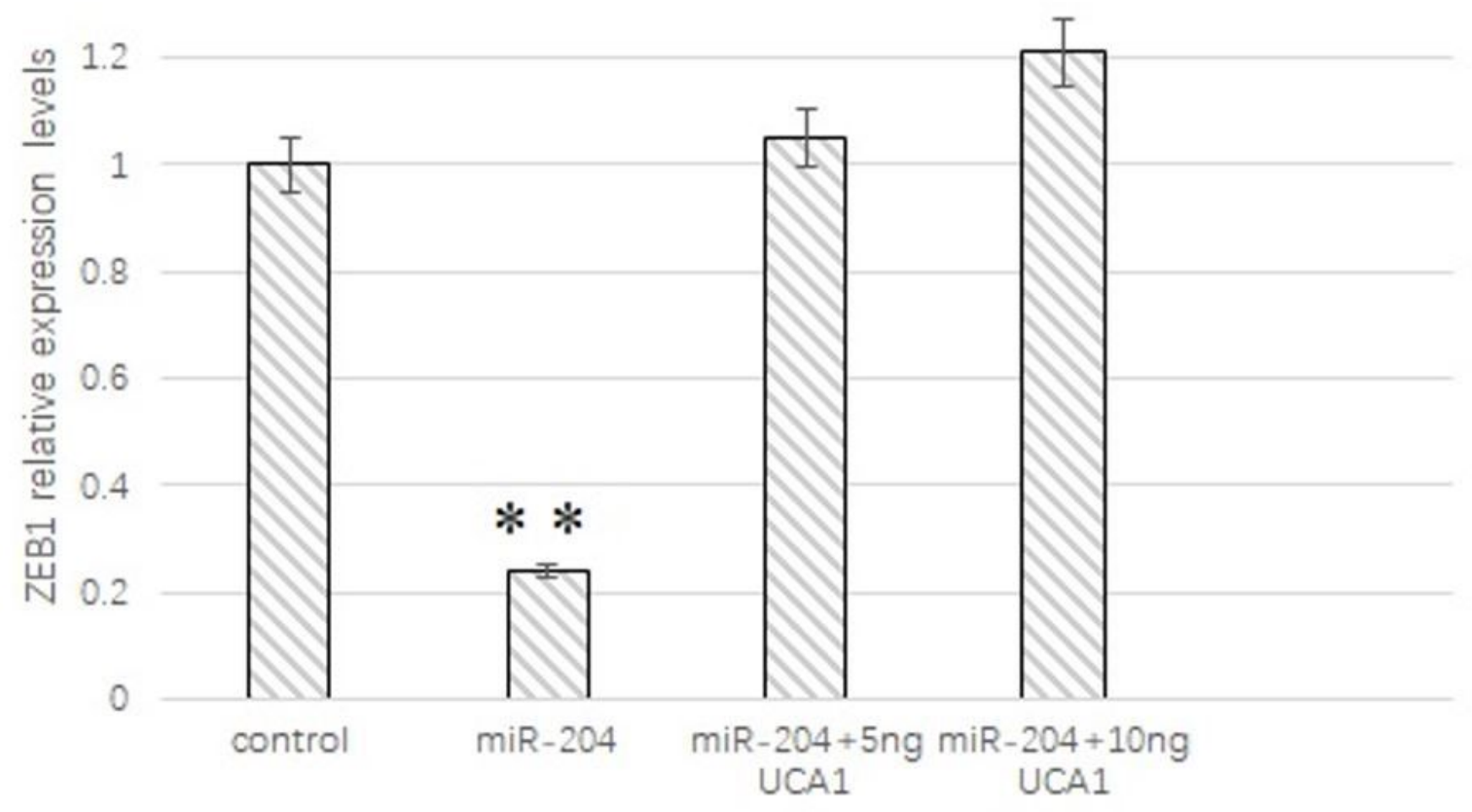

Figure 4

UCA1 sponges miR-204 to inhibit its function MNK-45 cells are transfected with three groups of genes separately: miR-204, miR-204+5ng UCA1 plasmid, and miR-204+10ng UCA1 plasmid. miR-204 transfection reduces ZEB1 expression to $0.24 \pm 0.03$. 5ng UCA1 and 10ng UCA1 can rescue ZEB1 expression to $1.05 \pm 0.10$ and $1.21 \pm 0.23$. ${ }^{*} \mathrm{P}<0.05$. 


\begin{tabular}{|l|c|c|c|c|}
\hline & \\
\hline
\end{tabular}

Figure 5

miR-204 directly reduces TGF- $\beta$ induced EMT related gene expression Three different combinations of genes are transfected into the MNK-45 cells. They are: TGF- $\beta$, TGF- $\beta+$ miR204, TGF- $\beta+$ miR204+UCA1. The four gene expression level changes are listed. ${ }^{*} P<0.05$.

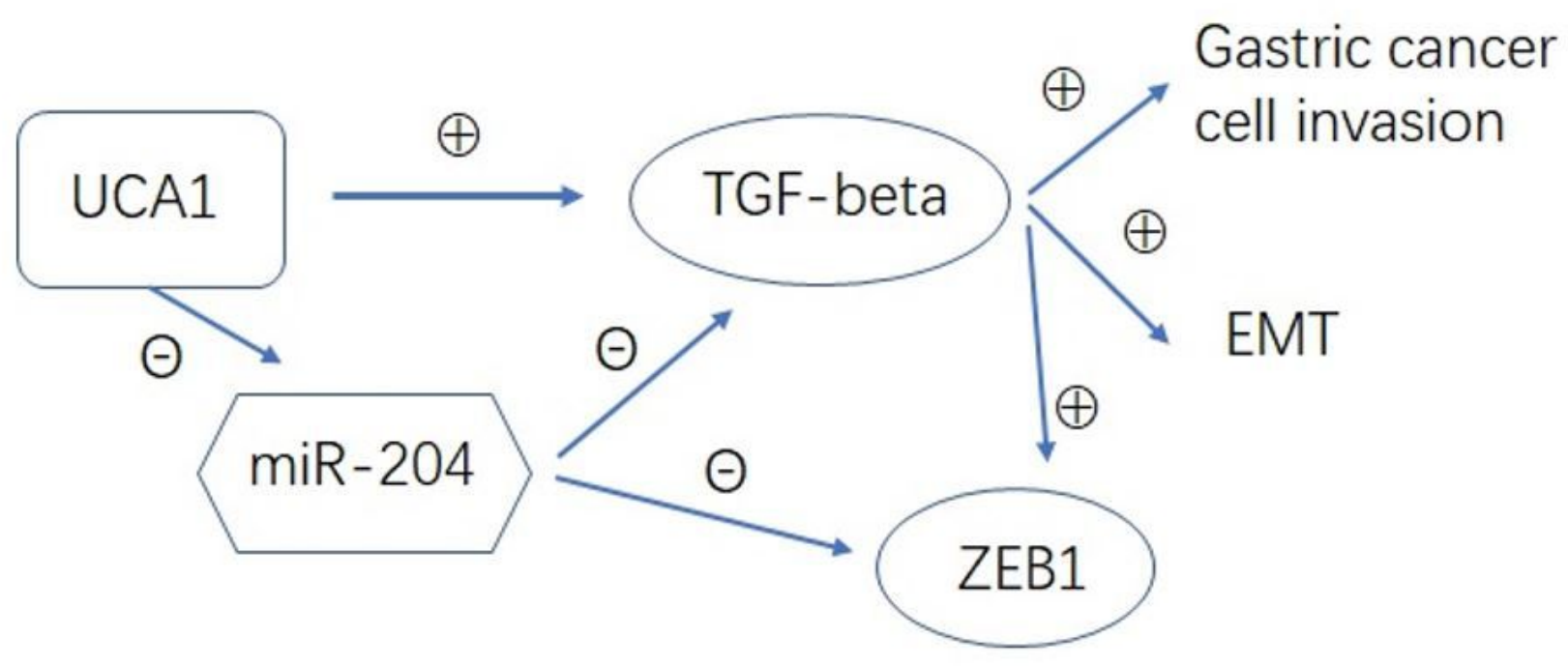


Figure 6

The cross-talk among TGF- $\beta$, UCA1 and miR-204 